\title{
Using Liminality and Subjunctivity to Better Understand How Patients With Cancer Experience Uncertainty Throughout Their IIIness Trajectory
}

Qualitative Health Research

$1-10$

(C) The Author(s) 2019

Article reuse guidelines:

sagepub.com/journals-permissions DOI: $10.1177 / 1049732319880542$

journals.sagepub.com/home/qhr

@SAGE

\author{
Stephanie Dauphin' (D), Steven Van Wolputte', Leontien Jansen', \\ Tine De Burghgraeve', Frank Buntinx ${ }^{1,2}$, and Marjan van den Akker ${ }^{1,2,3}$
}

\begin{abstract}
Uncertainty is a central theme in the illness experiences of older cancer patients throughout their illness trajectory. Mishel's popular theory on uncertainty during illness approaches uncertainty as an outcome and is characterized by the patient's inability to find meaning in illness events. This study used the concepts of liminality and subjunctivity to explore uncertainty throughout the illness trajectory of cancer patients. We interviewed 18 older (age range $=57-92$ years) patients with breast cancer or gastro-intestinal cancer 3 to 4 years post diagnosis. Our analysis is based on the QUAGOL guide that draws on elements of grounded theory such as constant comparison. We found that liminality and subjunctivity provide a useful frame for understanding uncertainty with a specific focus on its productive potential and meaning making. Health care professionals should be open to acquiring a complete picture of patients' diverse and dynamic experiences of uncertainty in the different stages of their illness trajectory.
\end{abstract}

\section{Keywords}

illness experiences; cancer patients; uncertainty; liminality; subjunctivity; qualitative research; Europe

\section{Introduction}

Uncertainty is an experience common to patients with cancer. Being diagnosed with cancer is seen as a lifechanging event often accompanied by psychological distress, which in turn has a negative effect on the patient's psychosocial wellbeing (Sajjadi, Rassouli, Abbaszadeh, Brant, \& Majd, 2016). A variety of studies have covered uncertainty in several cancer types and at various stages of the disease trajectory (Alberda, Alvadj-Korenic, Mayan, \& Gramlich, 2017; Gramling et al., 2018; Philip et al., 2018; Sasai \& Onishi, 2017; Shun, Chou, Chen, \& Yang, 2018; Zhang, 2017). Uncertainty can be related to the diagnosis, to new treatment or changes in treatment, and to medical follow-ups. It can also involve personal and social issues such as work, relationships, and identity. Uncertainty is not only limited to the active period of diagnosis and treatment but can also persist when treatment has finished and patients are well into a state of survivorship (Miller, 2012; Trusson, Pilnick, \& Roy, 2016).

Mishel (1988) developed a prominent "uncertainty in illness" theory that often serves as the blueprint for interventions and strategies for managing uncertainty in health care. According to Mishel (1981, 1988), uncertainty arises from cognitive processes that renders patients incapable of making sense of what is happening to them. Without tools to anticipate or predict future illness-related events, uncertainty comes into being. By reassessing the new situation and using coping strategies, uncertainty can be dealt with. Uncertainty can also be either perceived as a threat or an opportunity. Later, the theory was reconceptualized to include living with a chronic illness, meaning uncertainty could also be a part of the patient's everyday life (Mishel, 1990).

Most of the literature on uncertainty in illness has been written from a biomedical perspective that focusses on uncertainty as an outcome, identifying its causes and describing suitable interventions to "fix" or manage uncertainty (Bailey, Wallace, \& Mishel, 2007; Gil et al., 2006; Miller, 2012; Mishel et al., 2005; Mishel et al., 2009; Shaha, Cox, Talman, \& Kelly, 2008; Trusson et al., 2016).

'KU Leuven, Leuven, Belgium

${ }^{2}$ Maastricht University, Maastricht, The Netherlands

${ }^{3}$ Johann Wolfgang Goethe University, Frankfurt am Main, Germany

\section{Corresponding Author:}

Stephanie Dauphin, Academic Center for General Practice, Department of Public Health and Primary Care, KU Leuven, Kapucijnenvoer 33, P.O. Box 700I, 3000 Leuven, Belgium.

Email: stephaniedauphin84@gmail.com 
There has been little health research that provides a more holistic outlook. In our study, we found that uncertainty can be better understood as a process characterized by liminality and subjunctivity. Liminality refers to the ambiguous and fluid state in which cancer patients find themselves as a result of their diagnosis and subjunctivity highlights how uncertainty can be a form of action that creates space for multiple possibilities. We focus on how uncertainty is in itself a process of meaning making that emphasizes how cancer patients actively and productively engage the events they experience. This different understanding of uncertainty will aid health care professionals to see the potential uncertainty can hold. They can support patients in defining and locating possibilities for positive action throughout their illness trajectory. Patients themselves can be made more aware of how uncertainty can function throughout their illness trajectory.

\section{Method}

\section{Study}

The in-depth interviews, which form the base of this article, were conducted as part of the ongoing Kanker bij LIMburgse en Vlaams-Brabantse Ouderen Project (KLIMOP). This observational study aimed to examine the psychosocial wellbeing of older patients with cancer from a broad perspective (Deckx et al., 2011). There were three patient cohorts: older patients with cancer $(\geq 70$ years) and two control groups: middle-aged patients with cancer (50-69 years) and older patients without cancer ( $\geq 70$ years). We focused on the prevalence of psychosocial problems such as distress (Dauphin et al., 2019) and on patient experiences and key factors related to their well-being in their illness trajectory. A total of 18 in-depth interviews with 10 older and eight middle-aged cancer patients were conducted.

\section{Sample and Setting}

Patients were selected by means of purposive sampling from the three cohorts. They were contacted by telephone to explain the purpose of the interview. All but one selected patient accepted to participate in an in-depth interview. The refusing patient did not want to recall his illness experience in detail again. The first interview was conducted in October 2015 and the last in March 2017. All interviews took place at the patient's home and lasted between 45 and 90 minutes. There were no other people present at the interview except the researcher and the patient. We made use of a small topic list drawn up in consultation with the research team (i.e., the co-authors). We conducted three pilot interviews and used these experiences to adjust the topic list where necessary. Each interview commenced with the start of the patient's illness trajectory, asking, "can you tell me about when you were first diagnosed with cancer?" The researcher traced the patients' narrative of the illness trajectory as much as possible. From time to time, she asked for elaboration or prompted the patient to recount experiences in more detail. The interviews were audio recorded and transcribed verbatim. We continued interviewing until two independent researchers both agreed on data saturation.

\section{Analysis}

We coded, analyzed, and processed the interview transcripts through the use of NVivo qualitative software. For the analysis process, we used the QUAGOL guide: a comprehensive set of guidelines for structuring and deepening the analysis process (Dierckx de Casterlé, Gastmans, Bryon, \& Denier, 2012). This approach is characterized by an iterative process of constant comparison at various data stages based on grounded theory. We started after the first seven interviews. They were read in full to get a sense of the meaning of the whole interview. Phrases, words, and paragraphs deemed important were all underlined, with related notes and/or thoughts written about the essence of the interview. Later, we summarized each interview in a narrative report that included the key topics. We compared and discussed these narrative reports to see whether there was a consensus on the interviews' key storyline. Then, we transformed the narrative reports into conceptual schemes, moving from basic analysis to a conceptualization of the key experiences in the interview. These conceptual schemes were verified based on the raw interview data and were then further refined. On the basis of the conceptual schemes, a list of concepts was drawn up to create the coding tree. Subsequently, the other 11 interviews were conducted. The same aforementioned process was followed while simultaneously adding codes to the tree. This coding tree was constantly discussed, adapted, and verified against the raw interviews. The meanings of the concepts attributed to the codes were described and regularly narrowed down. This resulted in a framework in which the essential themes, subthemes, and their relationships capture the meaning of each interview in particular and the experiences of patients with cancer as a whole. The analysis generated essential findings central to the illness experience of our participants. The theme of uncertainty in the illness trajectory of cancer patients and how the concepts of liminality and subjunctivity characterized how the patients experienced uncertainty. These findings generated another round of analysis of the interviews with a focus on uncertainty, liminality, and subjunctivity to see whether there were relationships, links, or cues missed previously. 


\section{Participants}

The 18 interviewees consisted of 14 women and 4 men. Their age ranged from 57 to 92 years old at the time of the interview. All women and one man had breast cancer, while the three other men had gastro-intestinal cancer. The period between the diagnosis and the interview varied from 3 to 4 years after diagnosis. One patient relapsed during this period and was undergoing renewed treatment at the time of the interview. None of the other participants were actively being treated anymore. For them curative treatment had stopped within 1 year after diagnosis. Eleven patients were living with either their partner or child(-ren). One patient was living with her siblings, one patient was a nun in a convent, and one patient lived in a nursing home. The four remaining patients lived alone. Eleven patients had previously reported they had an informal caregiver, which in this case was their partner, child, or sibling. The majority left school between the ages of 15 and 18 years; at the time of interview, all patients were officially retired or no longer employed.

\section{Ethics}

This study was approved by the ethical review board of KU Leuven and UZ Leuven (S52097-ML6279). All participants signed informed consent, covering data collection for the entire study (Deckx et al., 2011).

\section{Context: Liminality and Subjunctivity}

The concept of liminality describing transition periods has gained increasing attention in health care research in recent years (Allan, 2007; Allan et al., 2015; Blows, Bird, Seymour, \& Cox, 2012; Bruce et al., 2013; Halliday, Boughton, \& Kerridge, 2015; Kosenko, Hurley, \& Harvey, 2012; Sabo, 2014). A concept originally coined by van Gennep (1960), liminality was used to describe certain life events people go through, such as pregnancy and marriage. These events are rites of passage, meaning people move from one state of being to the other and in so doing acquire a new social identity, status, and rank. There are individual and collective rites of passage which generally comprised three components: the rites of separation whereby a person severs all ties with their previous situation, the rites of transition whereby a person is "in between" social statuses, and the rites of reincorporation, whereby a person is reincorporated into a new social status with a new identity. Liminality or being in a liminal stage describes the transition phase. People are classified as being on the threshold of both the old and new, as being in an interim state, thereby positioning them in a state of ambiguity. They do not yet correspond with both the old or new categories and the associated identities, social norms, and practices. Victor Turner's (1969/2009) works have developed liminality into a favored concept. He classified liminal people, or entities, as "neither here nor there; they are betwixt and between the positions assigned and arrayed by law, custom, convention, and ceremony" (Turner, 1969/2009, p. 95). Liminality has been used in previous studies as a framework to understand and describe the cancer experience (Blows et al., 2012; Scott, 2014). We built further on this framework and introduce the analytical concept of subjunctivity as a way of understanding how patients engage liminality. Subjunctivity is closely tied to liminality described in Turner's (1974) later works on theater, ritual, and drama. His anthropological description-being on a threshold, being in-between - should be interpreted as being in a subjunctive mode. It is about potential, the "what if," the "maybe." It leaves room for possibilities. Susan Whyte $(1997,2002,2005)$ employed the concept in an analysis of the ways in which people in Eastern Uganda deal with misfortune and their health problems. It refers to a mood or attitude that emphasizes the actions people take to address the uncertainties they face in everyday life. It is "the mood of doubt, hope, will, and potential ... it is not a quality of life, or of particular persons, but a mood of action: a doubting, hoping provisional, cautious and testing disposition to action" (Whyte, 2005). Whyte's emphasis on the active component of subjunctivity and her application to a health care setting draws attention to the productive capacities of uncertainty when faced with a severe illness. By linking subjunctivity to liminality as a framework to understand the uncertainty experiences of patients with cancer, we add another dimension to the discussion of liminality in cancer.

\section{Findings}

Our analysis of the in-depth interviews revealed that the uncertainty patients experience features in three different periods throughout their illness trajectory. These periods are pre-diagnosis, during diagnosis and treatment, and posttreatment. In each of these periods, we can observe how liminality and/or subjunctivity provide a deeper understanding of the experience of cancer-related uncertainty. We show that liminality can be used to highlight essential features of uncertainty. And that patients employ a "subjunctive mood" when confronted with uncertainty which can be seen as a productive state.

\section{Pre-diagnosis Period}

In the pre-diagnosis period, preceding patients can experience certain (bodily) changes or symptoms that induce uncertainty or suspicion about their looming illness. When patients share this with others, be it a family 
member, friend, or health care professional, it is possible the other party downplays their signs. This downplaying can make them anxious and nervous or can even make them develop distrust about their own body and/or the health care system. Female patient $\mathrm{M}$ described that she was "nagging" about the thickening in her breast. She felt it was not just an inflamed mammary gland but possibly something more serious. She did not dare to complain to her husband or her general practitioner (GP) anymore because they previously waived away her concerns. Later on she found out she developed breast cancer, although in a different area of her breast. It is not uncommon for patients to feel uncertain about ambiguous symptoms or bodily sensations. In M's case, pressure from her husband prevented her from seeking help earlier. Unfortunately for $\mathrm{M}$, she also experienced other unexplained symptoms during this time which added to her uncertainty about her health and her self-image as a healthy person. Other patients also experienced uncertainty during the pre-diagnosis period and the majority regretted to some extent that they did not act on their "gut" feelings. Female patient A refrained from acting upon her suspicions because she had previous experience with nonmalignant tumors. She did not question her status as a healthy person because "if you had so many of those (nonmalignant tumors), you just think: it will be another one, the same." "And then when I had it checked it was too late and they had to remove them all (the lymph nodes)."

\section{Subjunctivity: Doing Nothing}

When patients experience uncertainty and do not engage it, there can still be an outcome, regardless of the situation. This outcome can be positive or negative, depending on how the patient (or others) interprets this outcome. Doing nothing can be interpreted as acting. Related to uncertainty, doing nothing is then used intentionally, as a deliberate tactic because it leaves room for imagination and multiple realities (Samuels, 2015). It is possible that patients actively seek uncertainty because it provides them with possibilities, and maybe even hope and security. Female patient $\mathrm{T}$ deliberately chooses this way of action in her pre-diagnosis period. She preferred to "be kept in the dark" for as long as she wanted, until she was more or less forced to engage with her illness:

I had it for two years without anyone knowing (Interviewer, "You had that for two years? And how did you find out?") Well, I had a lump in my chest. And I told the doctor, "Look there, I have a lump here." And he said, "Ah, but, you can let me take pictures, but I think it's more like a fat lump." But me and the clinic ... I say "Ah yes, well that's fine," and then I didn't pursue it further. I never went anywhere, and I said, "I will not have that," I say, "It will go away." And I got married in 2010 and there was nothing you could see from my appearance. And then in 2000- the $13^{\text {th }}$ of March $2011 \mathrm{I}$ started bleeding through my sweater. And then I had to tell my husband.

The example of $\mathrm{T}$ touches upon a different body of literature around interpreting and acting on symptoms. A patient's interpretation is informed by their social and cultural reality which in turn will influence their healthseeking behavior (Andersen, Paarup, Vedsted, Bro, \& Soendergaard, 2010). What is important here is that $\mathrm{T}$ actively seeks uncertainty and prefers it as a positive choice above certainty about her health. If she had known it was cancer at that time she feared it would have thrown her whole future, including her future marriage, into question. This course of action gave her the opportunity to envision an alternative future and to keep that idea alive for as long as possible.

\section{Diagnosis and Treatment Period}

When patients hear the diagnosis from their oncologist they are thrown into a liminal state. In that space and time, people are stripped of their old roles and statuses and transition into a new context. It marks a break with their old lives and heralds an undefined and unknown future. Uncertainty then becomes an embodied experience firmly rooted within the particular place and time of hearing the bad news. And even though for some patients the diagnosis did not come as a total surprise, the bad news had a severe impact. It was a life-changing event, ushering in a period punctuated by frequent hospital visits, surgery, therapies, medication, and the disruption of their everyday life. Male patient $P$ recalls,

Yes. That was actually a slap in the face. You don't consider it, you see. No, I would not have considered it and when you then hear: yes sir, you have, we have seen something in your gut, so we have removed lumps and there is something else there. And then you hear them say, a little bit later: yes, this afternoon the person responsible for surgery will come and he will make an appointment with you for surgery. [ ... ] But I was busy, and we went to Portugal a week later, on holiday. "Yes," said the surgical assistant, "that's fine, then you have all the time to prepare and so on." But, what do you want to prepare? You do not really know what it means or what's going to happen.

People lose control over their own time and schedule because of the transition into a patient status. All of a sudden they have to be present at appointments in hospitals or clinics or they are kept waiting in preparation of or recovery from (surgical) interventions. They feel as if they have to surrender themselves completely to the agenda and time-table of their doctor: 
Once they have you, they never let you go, right. Until your last day you must come at this and this hour. They don't ask: do you have someone to bring you, do you have someone who can arrange that? They don't ask you. You must be there. And then you would sit there for three hours in the corridor doing nothing. Between all those people. And this one complains and this one complains and those are fighting. And you sit there, staring.

\section{Subjunctivity: Social Relationships}

Receiving a cancer diagnosis can be a major stressful event, presaging a time of uncertainty and insecurity. Patients can use this uncertainty positively by carving out spaces and situations in which it becomes a resource, either personal or social. It enables them to renegotiate their relationships with others or with themselves. This is the subjunctive mood or action Whyte and Su (2015) and Grabska and Fanjoy (2015) focus on. It opens up space for hope, doubt, possibilities, and alternative futures. For female patient $\mathrm{G}$, it was an opportunity to try and re-establish her relationship with her son. They had lost contact a long time ago and she longed to reconcile with him and meet her grandchildren. She hoped disclosing her status could change the nature of their relationship. She mentions how anxious she was about her survival option and this forced her to take a decision:

I thought there might be something positive about this whole misery. I thought that this might make it right . . . And to start with, he [her husband] could not get any one to pick up when he called. They know that, they know who called (Interviewer, "Yes, so they did not pick up the phone?") No, and then I asked every time he came to the hospital: "And did you get L. on the phone?" No, but then one day, the second or the third day, he called L.'s work and got in touch with him. And then L. said, "Yes that is unfortunate" . . And then daddy paused for some time to give him the chance to say something, but he didn't and the telephone conversation ended like that.

Here, subjunctivity takes on the form of hope. It creates a space where a different scenario was possible; hope for something positive to come out of her uncertainty. Other patients also mentioned that their uncertainty gave rise to situations where they had hope, especially related to social relationships with loved ones, family, and friends. They actively sought out companionship and friendship because the diagnosis and treatment forced them to confront existential issues such as possible relapse or even death. Support from people around them helped to steer away from despair and remain hopeful for a positive outcome.

\section{Posttreatment Period}

When primary treatment ends, patients enter a transition period in which they have to adapt to a new life. They have to learn to live with possible side-effects or other lasting changes. For most patients, feelings of uncertainty diminished posttreatment. However, when it was time for a scheduled medical check-up, patients were more nervous and tense in the preceding days. After the appointment and when patients received positive news, uncertainty faded and they felt more secure about their own health. Feelings of uncertainty also flare up occasionally due to the sudden experience of unexplained or unknown symptoms:

Now I have to go back in the beginning of December, the 6th of December I have to go back and then it starts ...-Patient points to her forehead-What if they find something, what if they find something again?

Experiencing (dubious) symptoms is almost immediately linked to a possible relapse. Even when the symptoms are in another part of the body, the dread of possible cancer recurrence is usually the first thing that springs to the patient's mind. There are also patients that experience symptoms due to (long-lasting) side-effects of treatment. This uncertainty shapes their perspective on the present and the future and positions them in an ambiguous relationship to time. Male patient $\mathrm{N}$ experienced symptoms of severe dizziness and tinnitus and stated he was anxious about how this would affect his future:

I don't know what's in store for me, you know? You don't know, right? Will it stay like this in my head? I have no idea, you know? How long does that take? [ . . . ] It's in my head. And what happens with your head? Today, today is good, I'm already happy I'm not hearing any noise. But how long will it last? [Interviewer: "Yes. So you worry about that?"] Worry, yeah. Yes, how long does the dizziness last, for how long, you know? ... Can someone tell me that? I'm forced to think about it so much, but no one helps me. [ . . ] I'll tell you, I can't do it, OK? I don't know how long my head can take this.

Patients also talked about their situation as a period of enduring uncertainty, even when active treatment has ceased. There was disappointment about the fact their life and they themselves had changed, making it difficult to return to the way they were, "Everybody who has had cancer will tell you this: you will never be at ease. You will never be at ease. You will not be as before. It will never be like that again" (Emphasis added by the author.)

The posttreatment period gives rise to uncertainty shaped by the social relationships in which patients engage. Patients mention the perception and approach of others toward them can create feelings of uncertainty and feelings of unease related to their body, identity, and status. Whether or not patient disclosed their status to the outside world made a difference. But even those who were open about 
their illness experienced it as a continuous effort to find a new sense of equilibrium in life. Female patient $\mathrm{W}$ explains her struggle about identifying herself to the outside world. Is she still a patient or is she totally cured and thus a survivor? She experienced mixed feelings:

Then I say . . . I say now: I am a cancer patient now, although that is perhaps-I do not know-is that still now or after four years, you know? And I am a patient when the oncologist says so [ . . . I do not know how to deal with this in that area. It is what it is.

The relation between uncertainty and social relationships, which becomes apparent in the interaction and communication between patients and others, is inherently related to the social world around them. This is what Little, Jordens, Paul, Montgomery, and Philipson (1998) coined communicative alienation. Because others cannot relate to what the patient is going through, it is difficult to narrate and share the nature of their cancer experiences. The majority of our female patients talked about bodily and mental changes they experienced due to the diagnosis and/or treatment. They felt these changes harmed their femininity and body image. For female patient J, the loss of her hair and wearing a wig was a major issue. It did not only make her feel less of a woman, it also attracted unwanted attention to her liminal state as a cancer patient. Her hair was already growing back, but she still felt insecure and lacked the confidence to face the outside world. Her uncertainty evoked emotions of shame and taboo:

(She removes her wig) Slowly, slowly and now I'm a cancer patient again. (Interviewer: "Your hair color is nice.") Yes, but look (She turns around and shows me the back of her head, where her hair is much thinner). I can't go out on the street like that; I do not want people to see it all the time. I am a cancer patient. It's not something I'm proud of.

Throughout the posttreatment period, we noticed that (the need for) a subjunctive mood of action was not present in patients' accounts. Even though feelings of liminality still persisted, most patients explicitly expressed the need for control, closure, and a return to everyday life. This wouldat least partially - remove them from their liminal state and consequently place them in the state of reintegration, thereby commencing a new period in their illness trajectory and concluding their rite of passage. Uncertainty can then be integrated into their everyday life meaning patients are then able to "live with cancer" (Naus, Ishler, Parrott, \& Kovacs, 2009).

\section{Discussion}

\section{Summary}

When analyzing our in-depth interviews, we discovered uncertainty was a central theme featuring throughout the illness trajectory of patients with cancer. Further analysis led to the understanding that the illness trajectory of patients can best be divided into roughly three periods: pre-diagnosis period, diagnosis and treatment period, and posttreatment period. During these periods, experiences of uncertainty were identified as being liminal and subjunctive in nature. We came to the conclusion that Mishel's widely used theory about uncertainty in illness does not entirely reflect how patients with cancer experience uncertainty. She posits that uncertainty is seen as the outcome of patients not being able to make sense of what is happening to them. They cannot give meaning to their illness experience. We argue that when looking through the lens of liminality and subjunctivity, uncertainty can be understood as a process in which patients engage in meaning making. They do this at various stages in their illness trajectory and subjunctivity can take on various forms. In the pre-diagnosis period, some patients already experience uncertainty due to certain (bodily) symptoms or signs they cannot quite explain. Here, we see the start of the process of liminality that features throughout their illness trajectory. Their healthy self is called into question and forms a shaky base for the shock of the diagnosis. In this period, we identified doing nothing as a subjunctive action. At the time of diagnosis, feelings of liminality are pertinent and surrendering oneself to a medical context proved to have repercussions for possible reintegration into a new role and status as a patient. Liminal experiences are also visible within their social context. Social relationships can be a source of uncertainty, but its provisional nature can also spur patients into action and into collaborative engagement with their social environment. This is the subjunctive mood that can help patients gain something positive out of their cancer-related uncertainty. In the posttreatment period, feelings of liminality were still widespread and present for the patients in this study. How to relate to themselves and to others remained a challenge, as well as dealing with therapy side-effects, medical check-ups, fear of relapse, and bodily changes. In this period, our patients' accounts did not reveal subjunctive actions. The active search and need for closure of the illness trajectory and return to normal life was more important.

\section{Comparison to Previous Literature}

The time at which the cancer diagnosis was disclosed was a blow to all of the interviewees. It heralded a transition from a status of being a healthy individual to that of a patient and a transition into a period of constant change and challenges. After treatment, going for regular medical check-ups also meant patients reported heightened feelings of anxiousness and stress. And when experiencing either ambiguous symptoms or known side-effects of therapy, patients might also feel insecure or at risk of 
relapse. These findings are consistent with other research on cancer-related uncertainty in patients and even with research in patients with other diseases, such as HIV (Brashers, Neidig, Reynolds, \& Haas, 1998; Liao, Chen, Chen, \& Chen, 2008; Nelson, 1996; Pietilä, Jurva, Ojala, \& Tammela, 2018; Willig \& Wirth, 2019). Feelings of liminality pre-diagnosis have not received much attention in the literature (Granek \& Fergus, 2012). The focus is on the time around diagnosis or what Little et al. (1998, p. 1492) termed the phase of "acute liminality." They see this period as prior to a phase of sustained liminality, where the patient is more concerned with taking back control and constructing a new identity that gives meaning to the illness experience. Sustained liminality is an indefinite phase and usually ends with the death of the cancer survivor. In this period, recurrent screening and/or regular follow-up appointments contribute to fluctuating feelings of uncertainty, which was also the case for our patients. Liminality and accompanying challenges to one's identity and status as a cancer patient has also been documented in other articles (Gray et al., 2005; Miller, 2012; Navon \& Morag, 2004). Miller (2012) found that patients were constantly busy renegotiating their (new) identity vis-a-vis others. She also identified the interaction and communication with others as a source of uncertainty. These relational dimensions of uncertainty were also present in the experiences of our patients. We found that social relationships are not only a source of uncertainty and liminal feelings, they also harbor the productive potential of subjunctivity. Good et al. (1994) and Whyte (2002) have actively linked subjunctivity to patient's experiences with uncertainty in situations related to health care. Whyte (2002) describes how patients there prefer to remain oblivious about their HIV status and instead prefer to rely on other types of medicine and health care to maintain their health. Certainty about their HIV status means they could lose hope and consequently not deal with the consequences of a severe illness. It gives them the potential to ascribe meaning to unfolding illness events, whether positive or negative. In the literature, there exists a variety of perspectives and conceptualizations of meaning making (Park, 2010). No simple single definition exists but we noticed that by understanding uncertainty as a process featuring liminality and subjunctivity, meaning making was part of this process. Patients could make sense of what was happening around them, in contrast to what Mishel posits in her theory. Meaning making and coping are closely linked. Coping with cancer can take on many forms: physically, psychologically, spiritually, existentially, or religiously (Ahmadi, Park, Kim, \& Ahmadi, 2017; Ching, Martinson, \& Wong, 2012; Harrop et al., 2017). For Mishel, coping would be the means to an outcome: the management of uncertainty and resolving the situation. Our patients' stories indicate subjunctivity has a coping dimension because it can also be a source of help and support through their engagement with uncertainty. Our findings about the impact of cancer on femininity and body image resonate with the results of other studies with (mostly) breast cancer patients. There can be serious repercussions for a women's view of her body, her sense of self, and her intimate relationships (Godfrey, Price, \& Long, 2018; McCann, Illingworth, Wengström, Hubbard, \& Kearney, 2010; Parton, Ussher, \& Perz, 2016).

\section{Limitations}

Our participants suffered from either breast cancer or gastro-intestinal cancer, and at time of inclusion, all patients had a life expectancy of more than 6 months. It is likely that experiences of uncertainty in patients with a different tumor or metastatic or palliative patients are different from the experiences of our participants. We agree with Thompson (2007), who acknowledges that such a reductionist perspective leaves no room for the intersection of cancer with personal subjectivity. Also, the intersectionality between cancer and aging remains unexplored in this article. Our findings are based on an experience of participants $\geq 57$ years. Due to the design of the KLIMOP study that focusses on older patients with cancer, we did not include younger patients. It is likely that aging influenced how uncertainty is experienced in relation to the diagnosis and daily life of especially the older patients. Findings from Marshall, Grinyer, and Limmer (2019) about young adults with cancer indicate their adolescence served as a dual liminality in combination with their cancer diagnosis. It is possible that aging or (older) age could have been the source of liminal feelings in our patients. Some patients touched upon these issue of age and aging during the interviews but it was beyond our scope to include it in this analysis.

\section{Clinical Implications}

This study adds a different perspective and conceptual tools to enhance our understanding of uncertainty in the illness trajectory of patients with cancer. From it, we can discern important implications for clinical practice. Health care professionals that engage with these patients on a regular basis should be aware of the liminal character of uncertainty throughout the various stages in a patient's illness trajectory. By identifying the liminal dimensions of uncertainty, they can better relate to the experiences patients go through, not just during the acute period of diagnosis and treatment but also afterwards in the posttreatment period. They can then explore the resilient potential of uncertainty in patients' realities and contribute to the process of meaning making. It is beneficial 
that patients are given room and space to employ and expand their actions to counter (rising) uncertainty. Here, it is important to engage with patients on a more equal level and effectively give them ownership within their illness trajectory. Good and thorough communication between the patient and the doctor is then of utmost importance. In sum, patients can benefit from health care professionals open to acquiring a complete picture of patients' diverse and dynamic experiences of uncertainty in the different stages of their illness trajectory.

\section{Acknowledgments}

We would like to thank the patients who participated in our study for their willingness to share their experiences. We would also like to thank the reviewers for their critical comments that helped improve this article.

\section{Declaration of Conflicting Interests}

The authors declared no potential conflicts of interest with respect to the research, authorship, and/or publication of this article.

\section{Funding}

The authors disclosed receipt of the following financial support for the research, authorship, and/or publication of this article: This study was funded by Kom op Tegen Kanker, the campaign of the Vlaamse Liga tegen Kanker VZW.

\section{ORCID iD}

Stephanie Dauphin (iD) https://orcid.org/0000-0001-7594-2471

\section{References}

Ahmadi, F., Park, J., Kim, K. M., \& Ahmadi, N. (2017). Meaning-making coping among cancer patients in Sweden and South Korea: A comparative perspective. Journal of Religion and Health, 56, 1794-1811.

Alberda, C., Alvadj-Korenic, T., Mayan, M., \& Gramlich, L. (2017). Nutrition care in patients with head and neck or esophageal cancer: The patient perspective. Nutrition in Clinical Practice, 32, 664-674. doi:10.1177/0884533617725050

Allan, H. T. (2007). Experiences of infertility: Liminality and the role of the fertility clinic. Nursing Inquiry, 14, 132-139. doi:10.1111/j.1440-1800.2007.00362.x

Allan, H. T., Magnusson, C., Horton, K., Evans, K., Ball, E., Curtis, K., \& Johnson, M. (2015). People, liminal spaces and experience: Understanding recontextualisation of knowledge for newly qualified nurses. Nurse Education Today, 35(2), e78-e83. https://doi.org/10.1016/j.nedt.2014.10.018

Andersen, R. S., Paarup, B., Vedsted, P., Bro, F., \& Soendergaard, J. (2010). "Containment" as an analytical framework for understanding patient delay: A qualitative study of cancer patients' symptom interpretation processes. Social Science \& Medicine, 71, 378-385.

Bailey, D. E., Wallace, M., \& Mishel, M. H. (2007). Watching, waiting and uncertainty in prostate cancer. Journal of
Clinical Nursing, 16, 734-741. doi:10.1111/j.13652702.2005.01545. $\mathrm{x}$

Blows, E., Bird, L., Seymour, J., \& Cox, K. (2012). Liminality as a framework for understanding the experience of cancer survivorship: A literature review. Journal of Advanced Nursing, 68, 2155-2164. doi:10.1111/j.13652648.2012.05995.x

Brashers, D. E., Neidig, J. L., Reynolds, N. R., \& Haas, S. M. (1998). Uncertainty in illness across the HIV/AIDS trajectory. Journal of the Association of Nurses in AIDS Care, 9(1), 66-77. doi:10.1016/s1055-3290(98)80078-2

Bruce, A., Sheilds, L., Molzahn, A., Beuthin, R., SchickMakaroff, K., \& Shermak, S. (2013). Stories of liminality. Journal of Holistic Nursing, 32(1), 35-43. doi:10.1177/0898010113498823

Ching, S. S. Y., Martinson, I. M., \& Wong, T. K. S. (2012). Meaning making: Psychological adjustment to breast cancer by Chinese women. Qualitative Health Research, 22, 250-262. doi:10.1177/1049732311421679

Dauphin, S., Jansen, L., De Burghgraeve, T., Deckx, L., Buntinx, F., \& van den Akker, M. (2019). Long-term distress in older patients with cancer: A longitudinal cohort study. BJGP Open. doi:10.3399/bjgpopen19X101658

Deckx, L., Van Abbema, D., Nelissen, K., Daniels, L., Stinissen, P., Bulens, P., . . . van den Akker, M. (2011). Study protocol of KLIMOP: A cohort study on the wellbeing of older cancer patients in Belgium and the Netherlands. BMC Public Health, 11(1), Article 825. doi:10.1186/1471-245811-825

Dierckx de Casterlé, B., Gastmans, C., Bryon, E., \& Denier, Y. (2012). QUAGOL: A guide for qualitative data analysis. International Journal of Nursing Studies, 49, 360-371. doi:10.1016/j.ijnurstu.2011.09.012

Gil, K., Mishel, M. H., Belyea, M., Germino, B. B., Porter, L., $\&$ Clayton, M. (2006). Benefits of the uncertainty management intervention for African American and white elderly breast cancer survivors: 20-month outcomes. International Journal of Behavioral Medicine, 13, 286-294. doi:10.1207/ s15327558ijbm1304 3

Godfrey, M., Price, S., \& Long, A. (2018). Unveiling the maelstrom of the early breast cancer trajectory. Qualitative Health Research, 28, 572-586. doi:10.1177/1049732317746378

Good, B. J., Del Vecchio Good, M., Togan, I., Ilbars, Z., Güvener, A., \& Gelişen, I. (1994). In the subjunctive mode: Epilepsy narratives in Turkey. Social Science \& Medicine, 38, 835-842. doi:10.1016/0277-9536(94)90155-4

Grabska, K., \& Fanjoy, M. (2015). 'And When I Become a Man': Translocal coping with precariousness and uncertainty among returnee men in South Sudan. Social Analysis, 59(1), 76-95.

Gramling, R., Stanek, S., Han, P. K. J., Duberstein, P., Quill, T. E., Temel, J. S., . . . Norton, S. A. (2018). Distress due to prognostic uncertainty in palliative care: Frequency, distribution, and outcomes among hospitalized patients with advanced cancer. Journal of Palliative Medicine, 213, 315-321. doi:10.1089/jpm.2017.0285

Granek, L., \& Fergus, K. (2012). Resistance, agency, and liminality in women's accounts of symptom appraisal and 
help-seeking upon discovery of a breast irregularity. Social Science \& Medicine, 75, 1753-1761.

Gray, R. E., Wassersug, R. J., Sinding, C. M., Barbara, A., Trosztmer, C., \& Fleshner, N. (2005). The experiences of men receiving androgen deprivation treatment for prostate cancer: A qualitative study. The Canadian Journal of Urology, 12, 2755-2763.

Halliday, L. E., Boughton, M. A., \& Kerridge, I. (2015). Liminal reproductive experiences after therapies for hematological malignancy. Qualitative Health Research, 25, 408-416. doi:10.1177/1049732314550006

Harrop, E., Noble, S., Edwards, M., Sivell, S., Moore, B., \& Nelson, A. (2017). Managing, making sense of and finding meaning in advanced illness: A qualitative exploration of the coping and wellbeing experiences of patients with lung cancer. Sociology of Health \& Illness, 39, 1448-1464.

Kosenko, K. A., Hurley, R. J., \& Harvey, J. A. (2012). Sources of the uncertainty experienced by women with HPV. Qualitative Health Research, 22, 534-545. doi:10.1177 /1049732311424404

Liao, M., Chen, M., Chen, S., \& Chen, P. (2008). Uncertainty and anxiety during the diagnostic period for women with suspected breast cancer. Cancer Nursing, 31, 274-283. doi:10.1097/01.ncc.0000305744.64452.fe

Little, M., Jordens, C. F., Paul, K., Montgomery, K., \& Philipson, B. (1998). Liminality: A major category of the experience of cancer illness. Social Science \& Medicine, 47, 1485-1494.

Marshall, S., Grinyer, A., \& Limmer, M. (2019). Dual liminality: A framework for conceptualizing the experience of adolescents and young adults with cancer. Journal of Adolescent and Young Adult Oncology, 8(1), 26-31.

McCann, L., Illingworth, N., Wengström, Y., Hubbard, G., \& Kearney, N. (2010). Transitional experiences of women with breast cancer within the first year following diagnosis. Journal of Clinical Nursing, 19, 1969-1976.

Miller, L. (2012). Sources of cancer-related uncertainty survivorship. Journal of Cancer Survivorship: Research and Practice, 6, 431-440. doi:10.1007/s11764-012-0229-7

Mishel, M. H. (1981). The measurement of uncertainty in illness. Nursing Research, 30, 258-263.

Mishel, M. H. (1988). Uncertainty in illness. Image: The Journal of Nursing Scholarship, 20, 225-232.

Mishel, M. H. (1990). Reconceptualization of the uncertainty in illness theory. Image: The Journal of Nursing Scholarship, $22,256-262$.

Mishel, M. H., Germino, B. B., Gil, K. M., Belyea, M., LaNey, I. C., Stewart, J., . . Clayton, M. (2005). Benefits from an uncertainty management intervention for African-American and Caucasian elderly long-term breast cancer survivors. Psycho-Oncology, 14, 962-978. doi:10.1002/pon.909

Mishel, M. H., Germino, B. B., Lin, L., Pruthi, R. S., Wallen, E. M., Crandell, J., \& Blyler, D. (2009). Managing uncertainty about treatment decision making in early stage prostate cancer: A randomized clinical trial. Patient Education and Counseling, 77, 349-359. doi:10.1016/j.pec.2009.09.009

Naus, M. J., Ishler, M. D., Parrott, C. E., \& Kovacs, S. A. (2009). Cancer survivor adaptation model: Conceptualizing cancer as a chronic illness. Journal of Clinical Psychology, 65, 1350-1359. doi:10.1002/jclp.20622

Navon, L., \& Morag, A. (2004). Liminality as biographical disruption: Unclassifiability following hormonal therapy for advanced prostate cancer. Social Science \& Medicine, 58, 2337-2347. doi:10.1016/j.socscimed.2003.08.029

Nelson, J. (1996). Struggling to gain meaning: Living with the uncertainty of breast cancer. Advances in Nursing Science, 18(3), 59-76.

Park, C. L. (2010). Making sense of the meaning literature: An integrative review of meaning making and its effects on adjustment to stressful life events. Psychological Bulletin, 136, 257-301. doi:10.1037/a0018301

Parton, C. M., Ussher, J. M., \& Perz, J. (2016). Women's construction of embodiment and the abject sexual body after cancer. Qualitative Health Research, 26, 490-503. doi:10.1177/1049732315570130

Philip, J., Remedios, C., Breen, S., Weiland, T., Willenberg, L., Boughey, M., \& Weil, J. (2018). The experiences of patients with advanced cancer and caregivers presenting to emergency departments: A qualitative study. Palliative Medicine, 322, 439-446. doi:10.1177/0269216317735724

Pietilä, I., Jurva, R., Ojala, H., \& Tammela, T. (2018). Seeking certainty through narrative closure: Men's stories of prostate cancer treatments in a state of liminality. Sociology of Health \& Illness, 40, 639-653.

Sabo, B. (2014). Waiting and liminality: A phenomenon of spousal caregiving? Cancer Nursing, 37, 184-188. doi:10.1097/ncc.0b013e31828ee266

Sajjadi, M., Rassouli, M., Abbaszadeh, A., Brant, J., \& Majd, H. A. (2016). Lived experiences of "illness uncertainty" of Iranian cancer patients. Cancer Nursing, 39(4), E1-E9. doi:10.1097/NCC.0000000000000282

Samuels, A. (2015). Narratives of uncertainty: The affective force of child-trafficking rumors in postdisaster Aceh, Indonesia. American Anthropologist, 117, 229-241. doi:10.1111/aman. 12226

Sasai, T., \& Onishi, C. (2017). Relationship between uncertainty and emotions in advanced lung cancer patients after initial therapy. The Journal of Medical Investigation, 64, 96-100. doi:10.2152/jmi.64.96

Scott, E. J. (2014). A legacy of lingering uncertainty: The experience of long-term cancer survivorship: A multiplecase study ( $\mathrm{PhD}$ thesis, University of Nottingham, UK). Available from http://eprints.nottingham.ac.uk

Shaha, M., Cox, C.L., Talman, K., \& Kelly, D. (2008). Uncertainty in breast, prostate, and colorectal cancer: Implications for supportive care. Journal of Nursing Scholarship, 40, 60-67. doi:10.1111/j.1547-5069.2007.00207.x

Shun, S. C., Chou, Y. J., Chen, C. H., \& Yang, J. C. (2018). Change of uncertainty in illness and unmet care needs in patients with recurrent hepatocellular carcinoma during active treatment. Cancer Nursing, 41, 279-289. doi:10.1097/NCC.0000000000000487

Thompson, K. (2007). Liminality as a descriptor for the cancer experience. Illness, Crisis \& Loss, 15, 333-351. doi:10.2190/il.15.4.d 
Trusson, D., Pilnick, A., \& Roy, S. (2016). A new normal?: Women's experiences of biographical disruption and liminality following treatment for early stage breast cancer. Social Science \& Medicine, 151, 121-129. doi:10.1016/j. socscimed.2016.01.011

Turner, V. (1974). The forest of symbols: Aspects of Ndembu ritual. Ithaca: Cornell University Press.

Turner, V. (2009). The ritual process. New York: Aldine. (Original work published 1969)

van Gennep, A. (1960). The rites of passage. Chicago: University of Chicago Press.

Whyte, S. (1997). Questioning misfortune: The pragmatics of uncertainty in eastern Uganda. Cambridge, UK: Cambridge University Press.

Whyte, S. (2002). Subjectivity and subjunctivity: Hoping for health in eastern Uganda. In R. Werbner (Ed.), Postcolonial subjectivities in Africa (pp. 171-190). London: Zed Books.

Whyte, S. (2005). Uncertain undertakings: Practicing healthcare in the subjunctive mood. In R. Jenkins, H. Jessen, \& V. Steffen (Eds.), Managing uncertainty: Ethnographic studies of illness, risk and the struggle for control (pp. 245-264). Copenhagen, Denmark: Museum Tusculanum Press.

Whyte, S., \& Su, G. (2015). Contingency: Interpersonal and historical dependencies in HIV care. In E. Cooper \& D. Pratten (Eds.), Ethnographies of uncertainty in Africa (pp. 19-35). Houndmills, Basingstoke: Palgrave Macmillan.
Willig, C., \& Wirth, L. (2019). Liminality as a dimension of the experience of living with terminal cancer. Palliative and Supportive Care, 17, 333-337.

Zhang, Y. (2017). Uncertainty in Illness: Theory review, application, and extension. Oncology Nursing Forum, 44, 645649. doi:10.1188/17.onf.645-649

\section{Author Biographies}

Stephanie Dauphin is a $\mathrm{PhD}$ candidate at the Academic Centre for General Practice at KU Leuven.

Steven Van Wolputte is a professor at the Institute for Anthropological Research in Africa at KU Leuven.

Leontien Jansen is a $\mathrm{PhD}$ candidate at the Academic Centre for General Practice at KU Leuven.

Tine De Burghgraeve is a postdoctoral research fellow at the Academic Centre for General Practice at KU Leuven.

Frank Buntinx is emeritus professor at the Academic Centre for General Practice at KU Leuven and at the Department of Family Medicine, School CAPHRI, at Maastricht University.

Marjan van den Akker is a professor at the Institute of General Practice at Johann Wolfgang Goethe University, at the Department of Family Medicine, School CAPHRI, at Maastricht University and at the Academic Centre for General Practice at KU Leuven. 